Memória de uma cultura de resistência (Séculos VIII-XII)

\title{
Literatura Moçárabe
}

Memória de uma cultura de resistência (Séculos VIII-XII)

\section{António Rei}

\section{(2) OpenEdition \\ Journals}

\section{Edição electrónica}

URL: http://journals.openedition.org/medievalista/1047

DOI: 10.4000/medievalista.1047

ISSN: 1646-740X

\section{Editora}

Instituto de Estudos Medievais - FCSH-UNL

\section{Refêrencia eletrónica}

António Rei, «Literatura Moçárabe », Medievalista [Online], 4 | 2007, posto online no dia 05 março 2021, consultado o 25 março 2021. URL: http://journals.openedition.org/medievalista/1047 ; DOI: https:// doi.org/10.4000/medievalista.1047

Este documento foi criado de forma automática no dia 25 março 2021.

\section{(a) (1) \&}

Mediavalista está licenciado com uma Licença Creative Commons - Atribuição-NãoComercial 4.0 Internacional. 


\title{
Memória de uma cultura de resistência (Séculos VIII-XII)
}

\section{Literatura Moçárabe}

\author{
Memória de uma cultura de resistência (Séculos VIII-XII)
}

\section{António Rei}

\section{NOTA DO AUTOR}

Este texto é basicamente um dos capítulos da nossa Dissertação de Doutoramento (O louvor da Hispânia na cultura letrada medieval peninsular. Das suas origens discursivas ao apartado geográfico da Crónica de 1344, FCSH-UNL, 16 Julho 2007, policop.) que aqui apresentamos, e a que introduzimos ligeiras alterações. A principal contribuição a essas alterações provém da excelente antologia sobre a temática moçárabe e publicada agora mesmo em Março de 2008, pela Casa de Velázquez de Madrid, e intitulada ¿Existe una identidad mozárabe? Historia, lengua y cultura de los cristianos de al-Andalus (siglos IX-XII), Estudios reunidos por Cyrille Aillet, Mayte Penelas y Philippe Roisse, Madrid, Casa de Velázquez, 2008, [334 pp.], e da qual contamos dar em breve uma Nota de Leitura.

\section{Introdução}

2 As produções literárias moçárabes coexistiram sincronicamente, com produções e/ou tradições textuais cristãs não-moçárabes ${ }^{1}$ e, especialmente após o século $\mathrm{X}$, também com tradições textuais árabes.

Delimitaremos cronologicamente esta forma de cultura letrada e subalternizada, entre os séculos VIII (início da presença árabo-islâmica, que se manifesta por naturais reflexos político-culturais, neste caso para os hispano-godos submetidos ao novo poder) e o século XII (quando a 'Reconquista' peninsular já era comprometidamente romana cluniacense ${ }^{2}$, e quando as atitudes político-culturais dos novos reinos peninsulares, em consequência daquele compromisso, eram cada vez mais favoráveis ao 'apagamento' daquela minoria cristã mais ou menos arabizada). 
Veremos que alguns textos, independentemente das tradições textuais em que se integraram e das expressões culturais que lhes deram origem (cristã moçárabe, cristã não-moçárabe ou islamo-árabe), estavam unidos pelo facto de compartilharem algumas das suas fontes.

II. Especificidades da Cultura Moçárabe

6 A 'translacção' cultural moçárabe apresentou características próprias, as quais evidenciam sinais de um claro hibridismo cultural. Ao nível dos conteúdos são identificáveis - em primeiro lugar -, marcas de uma natural continuidade em relação ao que vinha do anterior período visigótico, e mesmo romano, pelo facto de os autores moçárabes continuarem sendo cristãos, como também o tinham sido os letrados visigodos, principalmente os que se conhecem como contemporâneos ou posteriores a $589^{3}$. Em segundo lugar, reconhecem-se, por vezes, também a incorporação de excertos provenientes de fontes árabes, facto também natural atendendo à sociedade em que os moçárabes estavam integrados.

7 Um outro aspecto importante sobre o papel dos moçárabes foi a contribuição que deram às traduções que foram feitas do latim para o árabe 4 .

8 Ao nível do discurso literário em si mesmo, parece constatar-se uma certa deriva que fez com que a inicial utilização do latim viesse a ser posteriormente substituído pelo idioma árabe ${ }^{5}$.

Outra característica da literatura moçárabe é o anonimato quase geral dos seus autores.

As obras surgem geralmente identificadas como Crónicas reportada a uma certa data, como no caso da Crónica Moçárabe de 754, ou a um determinado assunto. Não se lhes conhecem os autores, ou qualquer dado seguro a eles referente. Têm sido aventadas hipóteses, a maioria das vezes relativas às possíveis origens locais ou, quando muito, regionais, dos textos, atendendo geralmente às características textuais apresentadas.

III. Álvaro de Córdova e os meios letrados moçárabes dos séculos IX e X

11 Há, no entanto, uma figura que consideramos de importância em todo esse conjunto, mais ou menos nebuloso, da produção literária moçárabe. Trata-se de Álvaro de Córdova ${ }^{6}$. Embora não tenha sido, pelo que se sabe, autor de nenhuma obra de cariz historiográfico, os seus interesses e combatividade pela sobrevivência da cultura cristã peninsular fizeram-no ter interesse pelos textos antigos, alguns dos quais estudou e comentou ${ }^{7}$.

12 A emergência dramática do cristianismo em meados do século IX, na qual Álvaro de Córdova foi um dos principais intervenientes, acabou por dar origem, no seu extremo mais radical ao chamado 'movimento dos mártires de Córdova's. Mas deu origem também a iniciativas literárias, às quais não é difícil reconhecer também um carácter apologético, em especial na circulação dos textos chamados 'proféticos' ou 'pseudoproféticos', os quais, desde o século VIII, vinham propagando a ideia de que o fim do domínio islâmico estaria para breve ${ }^{9}$.

13 Assim, entre os finais do século IX e o início do segundo quartel do século X, é extremamente significativa a tradução das Historias de Orósio de latim para árabe. Aquela tradução da obra de Orósio terá sido levada a cabo pelo filho do mesmo Álvaro, Hafs ibn Albar (sendo 'Albar' a forma arabizada de Álvaro), então o Juiz dos cristãos cordoveses ${ }^{10}$. 

IX optou, assim, por uma metodologia de manutenção da cultura cristã-latina (aquela que seu pai já identificava como em clara decadência ${ }^{11}$ ), através da tradução para árabe daquela obra basilar da cultura medieval em geral, mas também, e especialmente, da cultura hispano-medieval.

A chamada Crónica Moçárabe de 754 (também conhecida como Continuatio Hispana) ${ }^{14} \mathrm{e}$ uma obra que terá sido composta em meados do século VIII, se atendermos àquela primeira forma que envolve uma datação.

19 É, portanto, contemporânea da crise que na Península se prolongou pela década de $40 \mathrm{e}$ que acompanhou, na década seguinte, a trágica mudança da dinastia califal no oriente, quando os Abássidas destronaram e massacraram os depostos Omíadas ${ }^{15}$.

20 Este texto reflecte de alguma forma, do ponto de vista cristão, a maneira como então aquela crise foi sentida em terras da Hispânia.

21 Historicamente a CM 754 é um dos poucos, e por isso tão importantes, textos cristãos peninsulares que se conhecem, e que foram compostos no período que medeia entre o reinado do monarca visigodo Wamba e o reinado do rei Afonso III das Astúrias, ou seja durante um lapso temporal de, pelo menos, dois séculos ${ }^{16}$.

22 A instabilidade político-militar que tinha tomado conta do espaço hispânico sob a autoridade islâmica, desde 740, com as revoltas berberes, veio a radicalizar-se após o derrube dos Omíadas em Damasco. Aquele conjunto de circunstâncias fez surgir, ou ao menos recrudescer, nos meios cristãos, a circulação e divulgação de textos pseudoproféticos, com cariz mais ou menos esotérico, e que prognosticariam o fim breve do domínio islâmico na Península.

Esta Crónica, de autor desconhecido, tem sido vista como produto de um círculo letrado moçárabe, sem que, no entanto, os investigadores tenham chegado a algum consenso

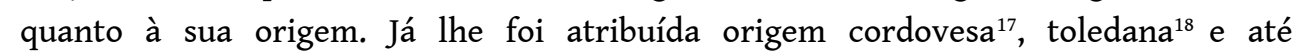
eventualmente murciana ${ }^{19}$.

24 Entre as fontes que foram utilizadas para a sua redacção contam-se a Crónica de João de Santarém ou de Bíclaro, na sua versão de 742, e a chamada Crónica Arábico-Bizantina de $741^{20}$.

A utilização posterior da CM 754, constatar-se-á mais tarde como fonte da Crónica Pseudo Isidoriana, numa última redacção ainda efectuada em meios moçárabes ${ }^{21}$; e já no período da 'reconquista' castelhano-leonesa na obra de Rodrigo Ximénez de Rada, como veremos adiante.

Uma particularidade textual que se verifica na $C M 754$ é o facto de integrar um novo elemento discursivo, de evidente origem cristã, e que fez história, pois continua a encontrar-se em textos de séculos posteriores. 

Ximénez de Rada e de Afonso X, respectivamente, De Rebus Hispaniae e Primera Crónica General, que vieram a ser compostas cerca de meio milénio depois da redacção da $C M$ $754^{22}$.

que tem sido designado como 'Dolo' ou 'Dó da Hispânia' é um discurso lamentoso, uma narração triste e dolorosa em que se relata que, em consequência do desaparecimento do Reino Visigodo e da instalação do poder islâmico na Hispânia, se tinham abatido sobre este extremo do mundo todas as desgraças e inclemências ${ }^{23}$. É o pranto pelo 'Paraíso Perdido', que urgia recuperar ${ }^{24}$.

Este 'dó' tinha uma função semelhante à da 'laude', ambos produzindo um efeito de exortação. No caso em que ambos se conjugam e complementam o efeito ganha muito maior impacto. A diferença essencial entre ambos é que a 'laude' exorta através da criação de uma exaltação positiva resultante de uma evocação da unicidade espaciotemporal da memória hispânica; enquanto o 'dó busca fazer surgir um sentimento negativo, resultante da evocação da diferença, do 'outro', e da condição 'estrangeira' do último e mais recente dos possessores da Hispânia, apresentando assim a sua ilegitimidade para nela continuarem ${ }^{25}$.

o 'dó ou 'dolo' terá sido o elemento emocional, o motor de arranque, da chamada 'Reconquista' que se foi elaborando posteriormente, em forma argumentativa, e enquanto discurso legitimador ${ }^{26}$.

31 V. Kitāb Hūrūšy̌ū̌s (KH) [O Livro de Orósio] (Sécs. IX-X)

32 As Histórias contra os pagãos, de Orósio, cerca de meio milénio depois da sua redacção, como já observámos em II.2., continuavam sendo uma referência-base de grande importância para a construção da memória hispânica. O Kitāb Hūrūšyū̌š (O Livro de Orósio) foi a 'ponte' através da qual muitos dos conceitos e memórias da Antiguidade Tardia relativamente à Hispânia, acabaram entroncando na cultura hispano-árabe. Trata-se, na sua origem, de uma tradução do latim para árabe das Histórias de Orósio ${ }^{27}$, obra considerada como uma matriz da historiografia medieval ${ }^{28}$ e de grande importância para esta Finisterra, por ser o autor da mesma um hispânico e a obra em causa dar um lugar especial à Hispânia ${ }^{29}$.

Até há pouco tempo esta tradução da obra orosiana era entendida como fruto de um trabalho de equipa, equipa essa dirigida, pelo Qādì (juiz) muçulmano Qāsim ibn al-Asbag̀ e constituída também pelo Juiz dos cristãos, um moçárabe ainda não identificado com segurança ${ }^{30}$. 0 texto latino em causa teria chegado a Córdova como oferta do Basileus de Constantinopla aquando de uma embaixada bizantina a al-Andalus ${ }^{31}$. $\mathrm{O}$ único ms. conhecido da tradução árabe de Orósio foi identificado há relativamente poucos decénios, em 1931, por I. Kratchkovsky ${ }^{32}$. Mas só em 1939 se pode dizer que foi então integrado nos meios científicos internacionais, pela mão de Levi Della Vida ${ }^{33}$. Deste ms. são conhecidas apenas duas edições, e algumas referências em artigos e obras mais gerais $^{34}$. No mais recente estudo e edição da obra, da autoria de Mayte Pénelas ${ }^{35}$, esta investigadora veio recolocar a questão da autoria da tradução, não apenas em relação aos seus executantes, mas também à metodologia da própria tradução e também ao círculo cultural que lhe deu origem; e, ainda, às motivações que tinham levado a que a mesma tradução tivesse vindo a acontecer.

Em função de tudo isto também é questionada a própria proveniência do texto latino que foi traduzido. Até então esta tradução tinha sido considerada como o trabalho de 
uma equipa de tradutores que se situava culturalmente junto ao círculos do novo poder califal. O objectivo ou objectivos da mesma poderiam ser um de dois, ou ambos em conjunto: enriquecer a biblioteca do príncipe al-Hakam, futuro califa e famoso bibliófilo; ou proporcionar um texto-matriz árabe que pudesse vir a ser utilizado na elaboração posterior de obras historiográficas articuladas com o novo regime e a nova ideologia califal. Facilmente se constata que qualquer um dos objectivos não exclui o outro, antes se podem interrelacionar estreitamente ${ }^{36}$.

Segundo Mayte Pénelas tratou-se afinal de uma tradução levada a cabo por Hafs ibn Albar, o filho de Álvaro de Córdova, então juiz dos cristãos da capital omíada. Ou seja, a aç̧ão de um juiz dos cristãos parece, portanto, confirmada. $O$ mesmo já não acontece com as demais anteriores conclusões ${ }^{37}$ que colocavam a possibilidade de Ibn al-Asbagh ter participado naquela empresa literária.

Pela sua condição de interlocutor privilegiado junto da corte, em nome dos cristãos cordoveses, Hafs ibn Albar seria um homem já culturalmente bilingue, pois falaria e escreveria o latim mas também o árabe, e a prova desse seu domínio da língua arábica seria, de forma patente, esta mesma traduçãa ${ }^{38}$.

Quanto à execução da mesma tradução a investigadora não aventa neste caso a proposta de que a mesma tivesse sido obra de uma 'equipa', pelo que teria sido muito possivelmente uma tradução levada a cabo apenas por um único homem, o filho de Álvaro de Córdova.

De forma semelhante à que identificámos supra quando referimos a $C M 754$, também aqui encontramos uma época de crise política em al-Andalus coincidindo com a produção de uma obra importante oriunda dos meios letrados moçárabes.

Na CM 754 foi a crise que decorreu entre 740 e 756; e neste caso coincide com o bastante mais longo período das autonomias muladis, que durante mais de meio século ${ }^{39}$, em especial no ocidente e no sul da Hispânia islâmica, eram a prova evidente da debilidade da autoridade política e militar dos emires de Córdova.

40 A herança cultural cristã procurava, pois, revivificar-se através de uma 'rememorização' de obras importantes da herança romano-visigótica, e, entre elas, a obra de Orósio, talvez a mais emblemática dos primórdios da cultura cristã hispânica.

41 Tratar-se-ia, pois, de mais um contributo para o espírito de resistência e de sobrevivência cultural das comunidades moçárabes.

42 No entanto aquela resistência já assumia formas aculturadas, pois apesar de haver a transmissão de uma memória cristã, a que acrescia o facto de ter origem hispânica, aquela transmissão já não se podia fazer em latim, tendo de ser feita em árabe.

43 A moçarabização, ou mais especificamente o grau de 'arabização' entre os cristãos peninsulares, estaria já muito avançada, em especial entre aqueles que residiam nos meios urbanos.

44 Ainda segundo Mayte Pénelas a questão que envolveria a chegada do texto das Histórias através da embaixada bizantina deixaria também de se colocar. Entende tratar-se afinal de um equívoco relacionado com outras ofertas de manuscritos pela mesma embaixada, mas em que não estaria integrada a obra de Orósio ${ }^{40}$.

45 Segundo esta autora as Historias contra os pagãos nunca teriam deixado de ser conhecidas e de circular na Hispânia, inclusive nos círculos letrados moçárabes ${ }^{41}$. E o facto de Hafs ibn Albar a ter conhecido e utilizado, tendo-a encontrado possivelmente entre os textos 
que tinham sido propriedade de seu pai, e de a ter transposto para a língua árabe, evidencia-nos, de facto, essa presença.

Ainda assim o texto árabe que hoje conhecemos do Kitāb Hūrūšȳūš (O Livro de Orósio em árabe $)^{42}$ não corresponde a uma mera tradução do texto latino das Histórias tal como genericamente é conhecido. Trata-se, ele mesmo, já de uma compilação textual, pois integra contribuições que provêm de fontes distintas das do texto matricial orosiano ${ }^{43}$.

Um pormenor, sem dúvida importante, e que, como exemplo, é revelador de alguma da metodologia utilizada na tradução / compilação, é o facto de o tradutor ter importado para a sua obra a estrutura textual da Chronica maiora de Isidoro de Sevilha, e não a que se constata nas mesmas Histórias de Orósio ${ }^{44}$.

$\mathrm{O} \mathrm{KH}$ veio a ser uma das fontes utilizadas por Aĥmad al-Rāzī para a sua obra perdida Akhbār Mulūk al-Andalus (Notícias acerca dos Monarcas de al-Andalus), certamente usada no apartado geográfico do seu trabalho, e que é o que mais especialmente nos interessa.

O mesmo $\mathrm{KH}$ veio a ser usado mais tarde, no séc. XI, por al-Bakrī na sua obra geográfica Al-Masālik wa-l-Mamālik (As Vias e os Reinos) ${ }^{45}$. A utilização do KH quer por al-Rāzĩ quer por al-Bakrī levanta importantes questões textuais que abordaremos em II.5.

VI. Crónica Pseudo-Isidoriana (CPs-I) (Séc. X-XI)

51 Obra que levanta vários problemas, em virtude de não se lhe conhecer o autor, o qual, sendo conhecido, ajudaria, com certeza, a datar, por aproximação, o período em que surgiu a obra em causa e a situar espacialmente o seu aparecimento.

52 Assim, relativamente a esta obra, quer a sua datação aproximada, quer a região da sua elaboração são questões importantes e ainda não sanadas ${ }^{46}$.

Tendo sido entendida como uma continuação da obra de Isidoro de Sevilha, tal facto deu origem à designação que surge no ms. de Paris: Cronica Gothorum a sancto Isidoro edita ${ }^{47}$. Mais recentemente, veio a fixar-se a sua denominação em Chronica Gothorum Pseudo Isidoriana ${ }^{48}$ ou simplesmente Crónica Pseudo Isidoriana (CPs-I) ${ }^{49}$.

Diversos autores que trataram este tema têm feito diferentes propostas no que toca à época da redacção desta Crónica ${ }^{50}$. Ramón Menéndez Pidal num primeiro momento entendeu tratar-se de uma obra compilada na primeira metade do século $\mathrm{XI}^{51}$, seguindo Mommsen e Cláudio Sanchez-Albornoz ${ }^{52}$, para depois se fixar na primeira metade do século $\mathrm{X}^{53}$. Levi Della Vida apontou, como possível época de redacção, o final do século $\mathrm{XI}^{54}$.

Pela nossa parte, cremos que todos têm uma parte de razão nas propostas que fazem. Assim, quanto a nós, a CPs-I será o resultado final de uma evolução textual que se foi processando ao longo dos séculos IX a XI. Seria um conjunto de textos que circulavam entre os letrados moçárabes e que foram sofrendo retoques e acrescentos, principalmente durante os períodos críticos, como foi o das autonomias muladis que tiveram lugar entre o último terço do século IX e o primeiro do século $\mathrm{X}$ ou a crise que levou à desagregação do Califado e ao início das Taifas ${ }^{55}$. $\mathrm{E}$, por último, e num cenário $\mathrm{e}$ numa lógica completamente diferentes, durante o período de resistência cultural que os moçárabes hispânicos protagonizaram na segunda metade do século $\mathrm{XI}^{56} \mathrm{e}$ no início do século XII, contra o cada vez maior predomínio do cristianismo romano e cluniacense, o qual acabou por vencer e levar, por parte das monarquias cristãs hispânicas, ao abandono do rito visigótico-moçárabe ${ }^{57}$. 
Atendendo ao cada vez maior grau de arabização dos moçárabes, a sua língua literária teria passado a ser o árabe, e nesse idioma terá sido ainda redigida a última versão da CPs-I. ${ }^{58}$

Enquanto texto, mantém ainda mais um outro conjunto de questões relacionadas com a forma como a CPs-I se articulará com o $\mathrm{KH}$ e com o $L R$, atendendo a algumas grandes semelhanças textuais entre todas. Nenhuma delas depende directamente de qualquer uma das outras,

$$
\begin{aligned}
& K H=C P S-I \neq L R \\
& \hline L R=C P S-I \neq K H \\
& \hline C P S-I=L R \neq K H \\
& \hline
\end{aligned}
$$

sendo de admitir a existência de um texto que serviu de fonte a todas e foi diferentemente aproveitado pelos autores; ou poderá ainda ter existido uma outra possibilidade, a qual abordaremos em seguida.

A génese destes textos parece ter-se dado durante a primeira metade do século X: o $\mathrm{KH}^{59}$ e a $C P s-I^{60}$ ligados ao espírito de resistência cultural moçárabe; e o $L R$, na sua versão primeira, das mãos dos al-Rāzī, ligado às memórias califais, mas iniciado por Aĥmad alRāzī, ainda no reinado de 'Abd al-Rahmān III' .

quer a CPs-I quer o $L R$ foram alterados nos séculos seguintes. A CPs-I presumivelmente, e com a sua versão final no último terço do século $\mathrm{XI}^{62}$; o $L R$, seguramente, refundido por Ibn Ġālib no terceiro quartel do século XII ${ }^{63}$.

61 Admitamos pois que o $\mathrm{KH}$ seja portanto a obra menos alterada desde a sua redacção / tradução, algures entre os finais do século IX e o primeiro terço do século X. Sem pretendermos formular uma conclusão, porque não cremos que existam dados para tal, queremos ainda assim levantar esta questão: sabendo-se que al-Bakrī também usou o $K H$ e que al-Bakrī foi usado por Ibn Gālib para redigir a sua obra, matriz do $L R$, e que a CPs-I pode também ter tido al-Bakrī como uma das suas fontes, ao menos na altura da sua tradução, já no século XII, então a compilação árabe desconhecida que deriva do $\mathrm{KH}$ e que foi usada quer pelo $L R$ quer pela CPs-I poderá ser a obra de al-Bakrī ${ }^{64}$.

É apenas mais uma proposta, que futuramente poderá vir a ser confirmada ou não, mas não é aqui o momento nem o local para esse estudo.

Admitir que a CMR não depende directamente da obra dos al-Rāzī e tomar esta hipótese anterior como uma conclusão de trabalho são pressupostos que poderão ajudar a clarificar situações textuais que envolvem quer os textos árabes quer as crónicas moçárabes e não só.

64 Compilada a CPs-I em ambiente moçárabe, usou entre as suas fontes a CM 754, a Historia Gothorum de Isidoro de Sevilha ${ }^{65}$; também se constatam passagens de João de Santarém e de Orósio, entre os autores hispânicos ${ }^{66}$, e ainda usou os códices moçárabes das Nomina Sedium ${ }^{67}$.

Trata-se, no seu conjunto, de uma síntese da História Hispânica, desde Noé até à invasão árabe, sendo introduzida por uma descrição geográfica da península ${ }^{68}$.

VII. As Nomina Sedium moçárabes 

referir são as chamadas Nomina Sedium, listas das divisões eclesiásticas da Hispânia, que embora compostas já durante o período de domínio islâmico, perpetuavam as divisões espaciais da igreja visigótica.

A criação daquelas circunscrições eclesiásticas era tradicionalmente atribuída ao imperador Constantino ${ }^{69}$ e a memória dessa mítica origem acabou passando mesmo para os textos árabes ${ }^{70}$.

Existem três códices moçárabes, anónimos, que foram recolhidos e editados por Simonet: o códice ovetense do Escorial, escrito em 780; o códice moçárabe do século IX; e o códice conciliar da Biblioteca Nacional de Madrid ${ }^{71}$.

Todos aqueles códices provirão da chamada "divisão de Wamba", texto que descreve uma repartição e definição dos limites entre as diferentes dioceses hispânicas. $O$ texto primitivo dessa divisão remete para o rei Wamba, rei visigodo que reinou entre $672 \mathrm{e}$ $680^{72}$ e que presidiu a um Concílio onde se teriam reunido todos os bispos da Hispânia ${ }^{73}$.

71 Aqueles códices moçárabes atrás citados serviram, mais tarde, de fontes, num caso ainda em meio cultural moçárabe, ao compilador da CPs-I e, já no século XIII, no meio cultural da monarquia leonesa, à Chronica de Lucas de Tuy ${ }^{74}$.

Apesar da sua origem moçárabe as Nomina também foram utilizadas por autores hispano-árabes. Uma das utilizações mais extensas das Nomina é a que remeterá para Aĥmad al-Rāzī, e que Ibn Ġālib terá mantido. Al-Bakrī também as utilizou, chamandolhe 'de Constantino"75.

73 E uma prova evidente dessa utilização aconteceu após a conquista de Valência por Jaime I o Conquistador, rei de Aragão, em 1239. Existindo uma disputa entre Toledo e Tarragona relativamente ao bispado de Valência então recém-restaurado, os nome dos dois al-Rāzī e de al-Bakrī foram citados como autores de obras passíveis de serem usadas como critérios para ajudar naquela delimitação das arquidioceses. As obras daqueles autores acabaram mesmo por ser utilizadas e, em virtude das informações nelas contidas, ficou então comprovado que Valência, no período visigótico, era um bispado sufragâneo de Toledo, e não de Tarragona ${ }^{76}$.

74 VIII. Conclusão

75 A cultura moçárabe, foi, enquanto existiu, produto da herança cultural hispanovisigoda em contínua relação e consequente aculturação com a cultura islamo-árabe que se instalou na Península Ibérica.

76 Uma das principais razões da sua existência e, eventualmente, o principal valor da sua identidade, foi o da resistência aos poderes hegemónicos que se lhe foram impondo. Foram de alguma maneira os herdeiros de uma cultura intrinsecamente hispânica, a qual se assumira politicamente com a aç̧ão unificadora da monarquia visigótica, e culturalmente fora elevada a hino laudatório por Isidoro de Sevilha

77 Mas, também, por outro lado, e apesar da existência de fronteiras políticas e diacrónicas, apercebemo-nos de que não houve realmente fronteiras culturais entre a Hispânia visigótica, o al-Andalus hispano-árabe e a Hispânia neo-goda. 


\section{NOTAS}

1. Sobre as produções literárias no âmbito da monarquia asturiana, v. infra II.6 e também Manuel Díaz Y Díaz, "La historiografía hispana desde la invasión árabe hasta el año 1000", in De Isidoro al siglo XI, Barcelona, El Albir, 1976, pp.203-234, pp.212-229.

2. Em 1080 Afonso VI de Leão e Castela adoptara oficialmente o rito romano e abandonara o rito visigótico, comprometendo-se assim com Cluny e com Roma (A. Rucquoi, História medieval da Península Ibérica, Lisboa, Estampa, 1995, pp. 161-162). M. Díaz Y Díaz, diz que essa adopção e abandono simultâneos se teriam dado ainda com Fernando I, pai de Afonso VI, portanto em data anterior a 1065 (v. Idem, "Isidoro en la Edad Media Hispana" in De Isidoro al siglo XI, pp.141-201, p. 184 n.121). Sobre influências cluniacenses na Hispânia do século XI, v. José Mattoso, "O monaquismo ibérico e Cluny", in Religião e cultura na Idade Média portuguesa, Lisboa, INCM, 1982, pp. 55-72.

3. Quando ocorreu a conversão de Recaredo ao catolicismo, abandonando o arianismo (A. Rucquoi , Op. cit., p.38).

4. V. infra n. 10.

5. Sobre a vivência cultural dos moçárabes e do seu papel na cultura hispânica daqueles séculos, v. M. Díaz Y Díaz, De Isidoro al siglo XI. Ocho estudios sobre la vida literaria peninsular, Barcelona, El Albir,1976; Maria Jesús Viguera, “Los mozárabes”, Actas do Congresso Proyección histórica de España en sus tres culturas, Valladolid, Junta de Castilla y León, 1993, pp.205-216; e ainda Isidro de las Cacigas, Los Mozarabes, II vols., Madrid, CSIC, 1947-48; e Francisco Javier Simonet, "Historia de los mozarabes de España", Memórias de la Real Academia de la História XIII (1897-1903).

6. Sobre Álvaro de Córdova, v. Isidro de las Cacigas, Los mozarabes, II vols., Madrid, CSIC, 1947-48, pp. 179-271. Em referência ao filho de Álvaro, Hafs ibn Albar (v.infra), é dito que descendiam de Aquila, filho de do rei Vitiza (CMR, ed. Catalán e Andres p. XLIX). Pertenciam pois à elite cristã hispânica, sendo descendentes de um monarca visigodo.

7. Relativamente à actividade literária (anotações e comentários) de Álvaro de Córdova a textos anteriores, v. M. Díaz Y Díaz, "Cultura literária en la España visigótica”, in De Isidoro al siglo XI, pp. 57-86, p. 71; Idem, "La circulation des manuscrits dans la Péninsule Ibérique du VIIIe au XIe siècle", Cahiers de Civilisation Médiévale (CCM) nº12, pp. 219-241 e 383-392, p. 225. Entre as obras de que Álvaro foi autor, as mais conhecidas foram o Indiculus luminosus (Indículo luminoso) e a Vita Eulogi (Vida de Eulógio) (I.Cacigas, Op..cit., I, pp.207 e 231-232).

8. Sobre o movimento dos 'mártires de Córdova', v. Isidro de las Cacigas, Op..cit., vol. I, em especial pp. 179-271. V. ainda E. Lévi-Provençal, "La oposición mozárabe en Córdoba (850-859)", in Historia de España - Menéndez Pidal, vol.IV, $4^{\mathrm{a}}$ ed., Madrid, Espasa-Calpe, 1976, pp.150-159.

9. L.Krus, "Tempo de godos e tempo de mouros. As memórias da Reconquista" in Passado Memória e Poder na sociedade medieval portuguesa. Estudos, Redondo, 1994, pp. 103-127, p.116; Manuel Díaz Y Díaz, "La historiografía hispana desde la invasión árabe hasta el año 1000", pp.219-220; A. Rucquoi, Op. cit., pp. 97-99. Sobre a erudição dos meios culturais moçárabes, v. Cláudio SanchézAlbornoz, "San Isidoro, «Rasis» y la Pseudo Isidoriana", Cuadernos de Historia de España IV (1946), pp. 73-113, p.113.

10. Sobre a nova proposta de autoria da tradução da obra de Orósio de latim para árabe, que terá sido, afinal, obra de Hafs ibn Albar al-Qûtî, (ainda sobre este magistrado e letrado moçárabe, v. supra n.6) alterando quase por completo o cenário que tínhamos anteriormente relativamente a esta tradução, v. Mayte Pénelas, Op. cit., em especial pp. 27-42. É referido como 'Juiz dos cristãos cordoveses' em Idem, p. 32. Sobre a actividade de Hafs ibn Albar como tradutor, conhecem-se 
como suas quer a tradução atrás referida, quer também a dos Salmos de David, obra que hoje se encontra em Milão (Idem, pp. 34-35; A. Rucquoi, Op. cit., p.101).

11. Mayte Pénelas, Op. cit., p.37; José Eduardo López, "La cultura del mundo árabe en textos latinos hispanos del siglo VIII" in Islão e Arabismo na Península Ibérica. Actas do XI Congresso da UEAI, Universidade de Évora, 1986, pp. 253-271, p.253-254; A.Rucquoi, Op..cit., p.109; A. H. de Oliveira Marques, "O latim e os falares moçárabes", NHP II, pp. 208-211.

12. Sobre o grau de arabização dos moçárabes que teria levado Hafs ibn Albar a traduzir Orósio de latim para árabe, v. Mayte Pénelas, $O p$.cit., pp.40-42. Outros sinais do alto grau de arabização das elites moçárabes no século X são o facto de Recemundo de Córdova ter escrito o seu 'Calendário' em árabe, e tê-lo dedicado a al-Hakam II; segundo M. Díaz y Díaz também a CM 754 ou Continuatio Hispana (Bibl.Nac., Madrid, ms. 4879 [Gg. 132]) teria sido traduzida para árabe; e também Isidoro de Sevilha teria sido traduzido para árabe, e posteriormente utilizado por al-Râzî (v. M. Díaz y Díaz, “Isidoro en la Edad Media Hispana”, p. 174); também Mayte Pénelas refere as muitas anotações árabes que acompanham os mss. das Etimologias, e que fazem supor terem sido extraídas de uma tradução árabe (Idem, Op..cit., pp. 56-57 e n.172). Aquela mesma listagem encontra-se quase literalmente em A. Rucquoi, Op. cit., p.101. Os próprios Evangelhos foram traduzidos para árabe, acompanhados de apontamentos litúrgicos, o que nos fala do grau de aculturação entre os moçárabes, pelo menos os de meios urbanos, em especial Córdova. (Ma. Jesus Viguera, «¿Existe una identidad mozárabe? A modo de conclusión» in ¿Existe una identidad mozárabe? Historia, lengua y cultura de los cristianos de al-Andalus (siglos IX-XII), Estudios reunidos por Cyrille Aillet, Mayte Penelas y Philippe Roisse, Madrid, Casa de Velázquez, 2008, pp. 299-314.

13. Relativamente ao conceito de 'tristeza' ou 'dolo', e às questões com ele relacionados no âmbito da ideologia cristã de resistência, v. infra «IV. Crónica moçárabe de 754».

14. A designação de 'Continuatio Hispana' ou 'Continuatio Isidoriana Hispana' ficou a dever-se a T. Mommsen (v. Crónica Mozarabe de 754 [ed. crít. e trad. cast. de José Eduardo López Pereira), Anúbar Ed., Saragoça, 1980, p.19; Cláudio Sanchéz-Albornoz, "La Crónica del Moro Rasis y la Continuatio Hispana", Anales de la Univ. de Madrid, Letras, III, 3 [1934]; e CMR, ed. Catalán e Andres, p. XXXV). Sobre edições e questões textuais relacionadas com esta Crónica, v. Crónica Mozarabe de 754 (ed. crít. e trad. cast. José Eduardo Lopéz Pereira), Anúbar Ed., Saragoça, 1980, em especial pp. 7-21; e M. Díaz y Díaz, "La historiografia hispana desde la invasión árabe hasta el año 1000" in, De Isidoro al siglo XI, Barcelona, Ed. El Albir, 1976, pp. 203-234, pp. 207-210; e Idem, "La transmisión del Biclarense", in De Isidoro al siglo XI, pp. 117-140; pp. 135-140; José Eduardo López, "La cultura del mundo árabe en textos latinos hispanos del siglo VIII", in Islão e Arabismo na Península Ibérica. Actas do XI Congresso da UEAI, Universidade de Évora, 1986, pp. 253-271, pp.267-269; B. Sanchéz Alonso, Historia de la historiografia..., pp. 105-108.

15. Sobre este período problemático na Hispânia islâmica em meados do século VIII, e os reflexos e consequências da mudança dinástica em Damasco, v. A. Rucquoi , Op..cit., pp.69-70.

16. Entre o reinado de Wamba (672-680) [A. Rucquoi, Op .cit., p.321] e o de Afonso III (866-909) [Idem, p.326], correram cerca de dois séculos, nos quais a produção literária foi muito escassa.

17. O partidário da origem cordovesa do autor é R. Dozy (apud M. Díaz y Díaz, “Transmisión...”, p. 135, n.44).

18. M. Díaz y Díaz, e já anteriormente Mommsen, entendiam ser o autor um toledano (Ibidem).

19. LÓPEZ PEREIRA entende ser alguém do sudeste peninsular, possivelmente murciano, o autor da CM754 (CM754, ed. López Pereira, p.17).

20. Sobre estes textos, o de 741 e o de 742, v. o excelente estudo de César Dubler, "Sobre la Crónica Arabigo-Bizantina de 741 y la influencia bizantina en la Península Ibérica", Al-Andalus XI (1946), pp. 283-349, sobretudo pp. 298-321; e ainda M. Díaz y Díaz, “Transmisión...”, pp.130-135. Cármen Hartmann, no estudo que acompanha a edição da Crónica de João de Santarém, diz ser a Crónica Arabigo-Bizantina de 741 um texto moçárabe (João de Santarém (Biclarense), Crónica [ed. e introd. C.C.Hartmann], p.80, n.143). 
21. Estamos em crer que a ultima redacção/versão da CPs-I, ainda em árabe, terá ocorrido em meio cultural moçárabe, e poderá ter sido uma peça instrumental importante na resistência cultural e identitária dos mesmos moçárabes, ante o avanço das influências borgonhocluniacenses. Pomos mesmo a possibilidade de que aquela redacção pode não ter sido algo de todo estranho a Sisnando Davidis, o homem que governou Coimbra e Toledo, entre 1065 e 1091 (sobre Sisnando Davidis, figura a pedir um novo estudo, ver a síntese, com 60 anos (!) mas ainda excelente, de Ramón Menéndez Pidal e Emilio Garcia Gomez, "El conde mozárabe Sisnando Davídiz y la política de Alfonso VI com los Taifas”, AA XII (1947), pp.27-41), e grande defensor da causa moçárabe, pois constata-se a presença da CM 754 em Coimbra, tendo sido fonte dos Annales Portugalenses Veteres (ainda sobre esta relação textual entre a CM 754 e os APV, v. Damião PERES, “A propósito do «Chronicon Alcobacense»", Rev. Portuguesa de História, I (1941), Univ. Coimbra, pp. 148-150 + 1 extratex.; José Eduardo López Pereira, "El elemento godo en los Annales Portugalenses Veteres: un problema de critica textual y de fuentes", Rev. Portuguesa de História, XVI (1976), Univ. Coimbra, pp.223-226), os quais foram redigidos até 1093 (João de Santarém (Biclarense), Crónica [ed. e introd. C.C.Hartmann], p.85) ou seja, durante o governo de Sisnando e de seu genro e sucessor, Martim Moniz. Curiosamente, o arquétipo textual da CM 754, que hoje conhecemos em vários testemunhos, parece remontar precisamente a Coimbra como ponto de origem (Idem, pp. 84-86; e António Benito Vidal, Crónica Seudo Isidoriana, Valência, Anúbar Ed., 1961, p.18), com excepção do chamado 'Complutense', que seria de Toledo (Idem, p. 86); mas Sisnando também governou Toledo. Se acrescentarmos a este quadro que Diego Catalán e Ramón Menéndez Pidal falam na redacção da CPs-I em Toledo (v.infra n.49), e que na sua composição os excertos de obras hispânicas são claramente privilegiados em relação a outros que o não são ( $C M R$, ed. Catalán e Andrs, p. XXXVII), o cenário de uma afirmação de cristianismo 'nacionalista', leia-se 'moçárabe', não parece descabido, nem toda esta conjectura de proximidade entre aquele magnate moçárabe, Sisnando, e este esforço cronístico com origem nos meios letrados do cristianismo hispânico. Sobre esta questão e período v. ainda Pierre David, "L'abolition du rite hispanique", Études Historiques sur la Galice et le Portugal du VIe au XIIe siècle, 1947, pp. 391-405.

22. O 'Dolo' constata-se ainda, como elemento exortativo, e sempre justaposto à 'Laude' no De Rebus Hispaniae de Rodrigo Ximénez de Rada ("Deploratio Hispanie", in De Rebus Hispaniae sive Historia Gothica [ed. e estudo Juan Fernández Valverde], Turnholt, Brepols Ed., 1987, pp.106-109) e na Primera Crónica General, de Afonso X ("Del duello de los godos de Espanna" in Primera Crónica General de España [ed. Ramón Menéndez Pidal], II ts., Madrid, Ed. Gredos, 1977, t.I, pp. 312-314).

23. Além das referências da nota anterior, v. "Spania miserrima" in CM 754 (ed. J.E. López Pereira), pp. 69-75.

24. Elisa Esteves, Op .cit., p. 91.

25. Sobre o 'Dó' ou 'Dolo' pela Hispânia, diz-nos Luís Krus: «As lamentações pela perda da Hispânia visavam um apelo à unidade cristã, o reforçar da resistência religiosa e cultural face aos novos poderes.» ("Tempo de godos e tempo de mouros. As memórias da Reconquista", p.108). Um reflexo evidente da divulgação deste texto poderão ter sido as revoltas moçárabes dos primórdios do século IX, que acabaram derrotadas e com a perda das autonomias das respectivas comunas (v. A. Rei, "Coimbra e a sua região, segundo as fontes geográficas árabes" in A cidade e o campo. Estudos de história rural e urbana oferecidos a Iria Gonçalves, FL-UL / FCSH-UNL, no prelo).

26. Sobre o conceito de 'Reconquista' e a sua difusão nos reinos cristãos peninsulares, v. J. Maravall, El concepto de España en la Edad Media, Centro de Estudios Constitucionales, Madrid, 1981 e Luís Krus, "Tempo de godos e tempo de mouros. As memórias da Reconquista" in Passado, Memória e Poder na sociedade medieval portuguesa, Patrimónia, Redondo, 1994, pp.102-127; e Idem, "Os heróis da Reconquista e a realeza sagrada medieval peninsular: Afonso X e a Primeira Crónica Geral de Espanha”, in Ibidem, pp.129-142. 
27. Acerca do conhecimento da existência desta tradução entre letrados dos séculos X e XI, v. Mayte Pénela, Op. cit., p.17.

28. C.Orcástegui e E. Sarasa, Op. cit., pp. 37-38. Sobre a popularidade desta obra na Idade Média, bastará dizer que se lhe conhecem cerca de 275 mss. (Orósio, História Apologética, pp. 34-43).

29. V. António Rei, O louvor da hispânia na cultura letrada medieval peninsular. Das suas origens discursivas ao Apartado Geográfico da Crónica de 1344, FCSH-UNL, 16 Julho 2007, policop., Cap. II.2.

30. Esta tese, de uma equipa chefiada por Ibn al-Asbagh, tem sido geralmente aceite (embora M. Díaz y Díaz já tivesse colocado anteriormente, em 1970 e em reedição de 1976 [Idem, "La Historiografia Hispana...", p.205], como data e local da redacção do $K H$, respectivamente, por volta de 930 e em Toledo [Idem, p.211]) até à muito recente investigação e edição que Mayte Pénelas levou a cabo, e onde foi formulada esta nova tese, quanto a nós bastante plausível. A anterior apresentava algumas debilidades cronológicas, quer relativamente ao monarca que hipoteticamente teria oferecido a obra a 'Abd al-Rahmān III (Mayte Pénelas, Op .cit., p.28); quer, e principalmente, no respeitante ao papel que o Qādī Qāsim ibn al-Asbağ teria desempenhado na empresa em causa, atendendo à sua idade e à sua sanidade mental no final da vida (Ibidem). 0 aspecto, até então acessório, que relacionava a tradução com os moçárabes passou agora a ser o aspecto principal e único (Idem, pp.30-42). A hipótese colocada por M. Díaz y Díaz situa aquela compilação ainda no ambiente da resistência toledana à política hegemónica de 'Abd al-Rahmān III.

31. V. nota supra.

32. Mayte Pénelas, Op. cit., p.83.

33. Ibidem, pp. 83-84.

34. As duas edições são: Ūrūsyūs, Ta'rikh al-'ālam, ed. 'Abd al- Rahmān BADAWĪ, Beirute, 1982; e Kitâb Hurûshiyûsh, ed. e estudo Mayte Pénelas, Madrid, CSIC, 2001. Entre os artigos são de referir os de G. Levi della Vida, “The 'Bronze Era' in Moslem Spain”, JAOS 63 (1943), pp.183-190; Idem, "La traduzione araba delle Storie de Orosio", AA XIX (1954), pp. 257-293; Idem, "Un texte mozarabe d'histoire universale", Études d'orientalisme dédiées à la mémoire de Lévi-Provençal, Paris, 1962, I, 175-183; e mais recentemente Luís Molina, "Orosio y los geógrafos hispanomusulmanes", AQ V (1984), pp. 63-92; I. KAHĪLA, "Kitāb al-Tawārīkh li-Bawlws Ūrūsyūs”, RIEEI 23 (1985-86), pp. 119-138. Entre os capítulos queremos referir aquele que Husayn MU'NIS lhe dedicou em Ta'rikh al Jağrâfiya wa-l-Jag̉râfiyyûn fi-l-Andalus, Madrid, IEE, 1967, pp. 18-25. Mais alguns informações que propiciarão um ponto de situação mais completo sobre este ms. e respectivos estudos, em Mayte Pénelas, Op. cit., pp.18-19.

35. V. n. supra.

36. V. V. António Rei, O louvor da Hispânia na cultura letrada medieval peninsular..., Cap. II.5.

37. V. supra n. 29.

38. V. supra n. 7.

39. No extremo ocidente as revoltas muladis prolongaram-se de 866 (quando se deram as primeiras revoltas em Mérida; v. Maria Ángeles Pérez Álvarez, Fuentes árabes de Extremadura, Cáceres, Univ.Extremadura, 1992, p.106) a 930 (quando Badajoz se rendeu a 'Abd al-Rahmân III; Idem, p.124) embora só com a rendição de Toledo, em 932, se tenha dado a pacificação de alAndalus sob a autoridade do seu primeiro califa (v. António Borges Coelho, Portugal na Espanha Árabe (PEA), 2ªed. II vols., Lisboa, Caminho, 1989, vol.II, p.36).

40. Pelo que, segundo Mayte Pénelas, apenas teria sido oferecida pelo basileus Constantino VII Porfirogeneta ao Califa ‘Abd al-Raĥmān III a obra médica de Dioscórides (v. ob.cit., p.29).

41. Ibidem, p. 30.

42. O único ms. conhecido da tradução árabe das Histórias de Orósio, é o que existe na Columbia University de Nova Iorque, na "The Rare Book and Manuscript Library", com a cota: $\underline{\text { X.893.712H }}$ (Mayte Pénelas, Op. cit., p.83; M. Díaz y Díaz, “La Historiografia Hispana...”, p.210).

43. Sobre a composição e a estruturação textual do KH, v. Mayte Pénelas, Op .cit., pp. 47-49. 
44. Mayte Pénelas, Op. cit., p. 48.

45. Relativamente à utilização que al-Bakrī fez do KH, v. Mayte Pénelas, Op .cit., pp. 73-74; e António Rei, Memória de Espaços e Espaços de Memória. De Al-Razi a D.Pedro de Barcelos, Dissertação de Mestrado, FCSH-UNL, 2 Julho 2002, policop., p.134, n.5. Sobre a relação da al-Himyarī com o KH, v. Mayte Pénelas, Op. cit., pp.74-76.

46. Um ponto de situação relativamente recente, de 1996, sobre a obra e sobre os autores que a ela se têm dedicado, em Helena de Carlos Villamarín, op .cit., 241-249. Dando uma ideia geral das problemáticas, não dispensa, nalguns casos a consulta da obra ou obras referidas, como a antiga mas não dispensável obra de B. Sanchéz Alonso, Historia de la historiografia..., pp. 115-116.

47. O ms. $\mathrm{n}^{\circ} 6113$ da Biblioteca Nacional de Paris, único exemplar da CPs-I começa daquela maneira (apud P.Gautier-Dalché, "Notes sur la «Chronica Pseudo-Isidoriana», Annuario de Estudios Medievales 14 (1984), pp.13-32, p. 14). Edições desta Crónica: T. Mommsen, Monumenta Germaniae Historica, Auctores Antiquissimi XI, Chronica Minora II, pp.372-388; edição castelhana da CPs-I, da autoria de Antonio Benito Vidal, Crónica Seudo Isidoriana, Valência, Anúbar Ed., 1961. A mais recente edição, tradução e estudo deste ms. é: La chronica gothorum pseudo-isidoriana (ms. Paris BN 6113) , ed. crítica, trad. y estudio de Fernando González Muñoz, A Coruña, Toxosoutos, 2000. 0 facto de a termos encontrado só muito recentemente não permitiu que a tivéssemos tomado como texto-base neste estudo; no entanto a antiga edição de Benito Vidal, pelo facto de ser tão despojada, será sempre uma edição a ter e conta.

48. Ramón Menéndez Pidal, "Sobre la Crónica Pseudo Isidoriana", Cuadernos de Historia de España XXI-XXII (1954), pp. 5-15, onde assim a designa, apesar do título apresentar outra forma. Também Cláudio Sanchez-Albornoz a designa daquela forma no seu longo estudo "San Isidoro, «Rasis» y la Pseudo Isidoriana", CHE IV (1946), pp. 73-113.

49. Esta designação, hoje a mais comum, encontramo-la, entre outras, no título do trabalho de Menéndez Pidal (v. nota supra); no trabalho de P. Gautier-Dalché, Op. cit., passim; M. Díaz y Díaz, "La Historiografia Hispana...", pp. 211-212; e na edição castelhana da CPs-I, de Antonio Benito Vidal, Crónica Seudo Isidoriana.

50. Diego Catalán, a partir de Menéndez Pidal, coloca a redacção da CPs-I a acontecer em Toledo, do punho de um murciano (v. CMR, ed. CATALÁN e ANDRES, p. XXXII).

51. Ramón Menendez Pidal, "Sobre la Crónica Pseudo Isidoriana”, p.5.

52. Cláudio Sanchéz-Albornoz, “San Isidro, 'Rasis’ y la Pseudo-Isidoriana”, p.74; Mayte PÉNELAS, ob.cit., 68 , n. 227.

53. Ramón Menendez Pidal, "Sobre la Crónica Pseudo Isidoriana", p.13.

54. Apud Idem, p.5. Antonio BENITO VIDAL, diz que Levi della Vida coloca a redacção da CPs-I no século XII (Idem, ed. Crónica Seudo Isidoriana, p.7).

55. Relativamente à constituição e estruturação do texto da CPs-I, e à época em que começou a sua circulação entre as comunidades moçárabes, M. Díaz y Díaz, "La Historiografia Hispana desde la invasión árabe hasta el año 1000", pp.211-212.

56. Chegou a existir um pleito judiciário, em 1077, entre os partidários de ambas as liturgias, a romana e a hispano-visigótica (v. L. Krus, A concepção nobiliárquica do Espaço Ibérico (1280-1380), p. 72, n.70).

57. Relativamente a esse período e a alguns protagonismos dentro da resistência moçárabe, v. supra n. 20.

58. A versão que acabou mais tarde por ser traduzida para latim (P. Gautier-Dalché, Op. cit., pp. 23-26).

59. Mayte Pénelas, ob.cit., pp.30-41.

60. R.Menéndez Pidal, "Sobre la Crónica Pseudo Isidoriana”, p.13.

61. V. António Rei, O louvor da Hispânia na cultura letrada medieval peninsular..., Cap. II.5.

62. Levi della Vida, R.Menendéz Pidal (“Sobre la Crónica Pseudo Isidoriana”, p.13.) e M. Díaz y Díaz (“La circulation...", p.230 e n.71) falam no final do século XI. 
63. A. Rei, Memória de espaços..., pp. 133-140.

64. P.Gautier-Dalché apercebe-se de questões aparentemente sem resposta, fruto das suas confrontações textuais (Op. cit., pp. 20-21) (e que se poderão tentar solucionar a partir desta nova óptica proposta), bem como testemunhou passagens em que a 'CMR' e a CPs-I coincidem apenas com al-Bakrî (ob.cit., p. 23). Também Diego Catalán reconhece que existem contactos entre as três obras, e que a CPs-I e o LR dependerão de uma obra derivada do HK (Idem, ed. Crónica del Moro Rasis, p. LXI).

65. P. Gautier-Dalché, Op. cit., p.25.

66. Crónica Seudo Isidoriana, (ed. Antonio Benito Vidal), p.7.

67. V. infra VII.

68. Crónica Seudo Isidoriana, (ed. A. Antonio Benito Vidal), p.7.

69. J.Vallvé, La División ..., p. 182.

70. AL-BAKRĪ, al-Masālik wa-Mamālik, 2 vols.,ed. A. Van Leuwen e A. Ferrá, Cartago (Tunísia), al-Dār al-‘Arabiyya li-l-Kitāb, 1992, II vol., pp. 891-893; tradução parcial castelhana por E.Vidal Beltrán, Geografia de España, col. Textos Medievales, 53, Anubar, Saragoça, 1982, pp. 15-18.

71. Francisco Javier Simonet, "Historia de los mozárabes de España”, Memorias de la Real Academia de la Historia, XIII (1897-1903), pp.808-812; também referidos por J.Vallvé, Idem, p. 212, n. 114.

72. A. Rucquoi, Op. cit., p. 321.

73. Luis Vazquez de Parga, La División de Wamba. Contribución al estudio de la historia y geografía eclesiásticas de la Edad Media española, Madrid, CSIC, 1943, pp.70-72; J.VALLVÉ, Idem, p. 220.

74. J. Vallvé, Ibidem, pp. 212-223.

75. V. supra ns. 66 e 67.

76. Relativamente a este episódio demonstrativo da importância da recolha, por autores hispanoárabes, das divisões eclesiásticas hispânicas anteriores a 711, v. Pascual de Gayangos, "Memória sobre la autenticidad de la Crónica denominada del Moro Rasis", Memorias de la Real Academia de la Historia, VIII (1852), pp. 1-100, pp. 8-9. Sobre a identificação de 'Abiba Cacabahi' como 'Abū 'Ubayd al-Bakrī’, v. Husayn MU’NIS, Tā’rīkh al Jaġrāfia wa-l-Jaġrāfiyyūn fi-l-Andalus, pp. 71-72.

\section{AUTOR}

\section{ANTÓNIO REI}

Bolseiro FCT / Investigador do IEM - UNL 